\title{
DISENTANGLING THE DISTRIBUTIVE IMPACT OF FISCAL POLICY
}

\section{DESCOMPOSICION DEL IMPACTO DISTRIBUTIVO DE LA POLITICA FISCAL}

\section{WALTER CONT*}

CAF - Banco de Desarrollo de América Latina and Universidad Nacional de La Plata

\section{ALBERTO PORTO**}

Universidad Nacional de La Plata and Academia Nacional de Ciencias Económicas

\begin{abstract}
This paper provides a methodology to decompose the redistributive effect of fiscal policy for individual income units that belong to groups. This methodology is useful to identify how much of redistributive effect and also progressive/regressive effects apply within groups, between groups and among overlapping units, and whether there are tensions between different effects. A case study with an application of fiscal policy in Argentina for year 2010 is provided.
\end{abstract}

Keywords: Welfare Economics, Redistributive effect, Tax incidence, Expenditure benefits Measurement of Redistribution, Fiscal Policy.

JEL Classification: D63, H22, $H 23$.

* Corresponding author. E-mail: wcont@caf.com

** CEFIP-IIE-FCE-UNLP. E-mail: alberto@econo.unlp.edu.ar This paper is part of Proyecto PICT 2016-0338-FONCYT. 


\section{Resumen}

Este trabajo propone una metodología para descomponer el efecto redistributivo de la política fiscal para unidades individuales de ingreso cuando estas unidades pertenecen a grupos. La metodología es útil para desagregar cuánto del efecto redistributivo y de los efectos progresividad/regresividad se originan dentro de cada grupo, entre grupos, y por superposición de unidades, y si existen tensiones entre los efectos que resultan de esas desagregaciones. Se aporta como caso de estudio la ejecución de la política fiscal argentina en 2010.

Palabras clave: economía del bienestar; efecto redistributivo; incidencia impositiva; beneficio de gastos; medidas de redistribución; política fiscal.

Clasificación JEL: D63, H22, H23.

\section{INTRODUCTION}

Fiscal policy affects income distribution. The understanding of redistributive effects of fiscal policy has gained room since the paper by Musgrave and Thin (1948) almost seven decades ago. The contributions by Musgrave (1964), Reynolds and Smolensky (1977) and Kakwani (1977), among others, sprung a research agenda that is still fruitful nowadays. We identify four main contributions to the analysis of the redistributive effect: (i) the design of fiscal policy (size and progressiveness), (ii) the result of disentangling the effect by levels of government, (iii) the net effect of horizontal and vertical redistribution, and (iv) the effect of reranking on income redistribution. If an analysis of effects among different groups is relevant, literature has advanced on the last two sets of contributions. But a decomposition of vertical effect and of fiscal policy components in the presence of groups is lacking.

This paper introduces a methodology to decompose the distributive impact of fiscal policy (redistributive effect) that matches a decomposition of the reranking effect when individual units belong to identifiable groups. This approach matches the decomposition of the reranking effect provided by Monti et al. (2012). This way, we can identify how much of redistributive effect (and progressive / regressive effect) applies within groups, between groups and among overlapping units, and whether there are tensions between different effects.

We apply the measures to study the execution of consolidated (nation-provinces) fiscal policy in Argentina for year 2010, making use of previous results from Cont and Porto (2016a, 2017). Using this methodology, we find that the sources of personal income inequality in that year come from within-group (50 percent), differences in groups' average income (26 percent) and income overlapping of units belonging to different 
groups (23 percent). Income redistribution of consolidated fiscal policy represents 19 percent of ex ante inequality and is the net result of a vertical effect partially compensated by a small reranking effect. We cluster provinces and income units in groups according to socioeconomic indicators. Under this selection of groups, we find that vertical and reranking effects distribute within-group and across-group evenly. A deeper analysis that distinguishes provincial and national budgets provides further insights: provincial expenditure is found to be the most progressive tool, reducing inequality within groups (53 percent of the progressive effect of provincial expenditure), reducing disparities between groups (19 percent) and reducing overlapping of income units (28 percent). The progressive effect of national expenditure and the regressive effect of national taxes distribute evenly within and between groups. They do not contribute to increase or reduce overlapping of income units. The impact of provincial taxes is regressive, as the net result of within and overlapping effects, partially compensated by a progressive effect between groups. An analysis from another angle - fiscal policy classified into cash-in kind instruments- reveals that both kinds of expenditures are progressive and include a 50-percent within-effect. Cash transfers have little transvariation effect (cash benefits do not change relative net-incomes to overlapping units from different groups). Taxes are regressive in all dimensions, except for a progressive transvariation effect for ex-ante taxes (which partially compensates a regressive effect caused by higher taxes paid, in average, by income units belonging to poorer groups). Qualitatively similar results are obtained when analyzing the effect of fiscal policy on regional income distribution. Finally, the methodology can be applied to different group selection criteria and to fiscal policy in other countries.

The paper develops as follows. Section 2 presents a conceptual framework and the relevant literature that contributed to the redistributive effect of fiscal policy. Section 3 advances further in the decomposition of the redistributive effect when there are different groups of income units and presents the proposed methodology of the paper. Section 4 applies the results to the case of Argentina for year 2010. Section 5 engages in the decomposition of redistributive, vertical and reranking effects when income units are pooled in different groups. Section 6 concludes. Two Appendixes provide complementary information.

\section{FISCAL POLICY AND REDISTRIBUTION: VERTICAL AND RERANKING EFFECTS}

Let $X=\left\{x_{i}\right\}$ and $Y=\left\{y_{i}\right\}$ be two distributions of income for a population with $\mathrm{N}$ individuals. By assuming that individuals weigh $p_{i}$ ( $\operatorname{such}$ that $\left.\Sigma_{\mathrm{i}} p_{i}=1\right)$ the setup allows for flexible interpretations: they may be individual households $\left(p_{i}=1 / N\right)$ or weighted units such as provincial quintiles or provinces in a country (being $p_{i}$ the population size of a quintil-province or a province). We are interested in studying changes in income distribution caused by fiscal policy. Let 


$$
y_{i}=x_{i}+g_{i}-t_{i}
$$

where $x_{i}$ is ex ante income, $g_{i}$ is expenditure benefits, $t_{i}$ represents taxes and $y_{i}$ is ex post or extended income corresponding to individual unit $i$.

We use a measure to summarize inequality associated to each distribution of income. Let the concentration index for any distribution A, given the ordering of distribution $\mathrm{B}$, be $\mathrm{C}_{\mathrm{AlB}}$. For example, the distribution of ex post income, preserving the order according to ex ante income, is $\mathrm{C}_{\mathrm{Y} \mid \mathrm{X}}$. The Gini coefficient of inequality corresponds to the concentration index for distribution $\mathrm{A}$ given the ordering of this distribution. In this case, $\mathrm{G}_{\mathrm{X}}=\mathrm{C}_{\mathrm{X} \mid \mathrm{X}}$ and $\mathrm{G}_{\mathrm{Y}}=\mathrm{C}_{\mathrm{Y} \mid \mathrm{Y}}$.

A main concern of the literature on public finance has been the understanding of the effect of fiscal policy on income distribution, at least since the "welfare state" view of the theory of the state (Musgrave and Thin, 1948, Musgrave, 1996). An approach to analyze different measures of redistribution is the Redistribution Effect (RE), defined as the difference between ex-ante and ex-post Gini coefficients: ${ }^{1}$

$$
R E=G_{X}-G_{Y}
$$

where RE is definite positive if there is reduction of inequality (Kakwani, 1984, 1986, and Reynolds and Smolensky, 1977).

Given the information used in this paper, we consider the case that individual units have different ex ante income $\left\{x_{i}\right\}$. This way we disregard horizontal effects (i.e., unequal treatment of equals). ${ }^{2}$ A decomposition of the redistribution effect (1) is

$$
R E=\left(G_{X}-C_{Y \mid X}\right)+\left(C_{Y \mid X}-G_{Y}\right)=R S-R^{A P}=V^{K}-R^{A P}
$$

where the first term is the Reynolds-Smolensky effect of income redistribution positive definite- and the second term $R^{A P}$ is the "reranking effect" (Atkinson, 1980, Plotnick, 1981; see also Lambert, 1985, 1988). ${ }^{3}$ Kakwani $(1984,1986)$ showed that the redistributive effect is a "vertical" effect of fiscal policy if individual income units preserve their order in the original (ex-ante income) ranking: $R E=V^{K}$.

1 Other measures were proposed by Musgrave and Thin (1948): $R E^{M T}=\left(1-G_{Y}\right) /\left(1-G_{X}\right)$; and Kakwani (1984): $R^{K}=\left(G_{X^{-}} G_{Y}\right) / G_{X}$. Moreover, other authors explored measures of the redistributive effect in a context of general Welfare functions (Aronson, Johnson and Lambert, 1994; Duclos, Jalbert and Araar, 2003).

2 The analysis of pseudo horizontal effects is possible in this paper if we decompose the population in groups of "close equals" (van de Ven, Creedy and Lambert, 2001; Urban and Lambert, 2008). We do not pursue this line of research here but mention it in passing (see details in Feldstein, 1976).

3 At the time of the book by Reynolds and Smolensky (1977), reranking was not an issue and hence the RS effect was captured through $G_{X}-C_{Y \mid X}$ (see Urban, 2009). 
Both effects received significant attention in the literature. Consider first that income units do not reorder after fiscal policy, so that $C_{Y \mid X}=G_{Y}$. The RS effect is fully decomposed into fiscal-policy contributions (Reynolds and Smolensky, 1977). Taking the results from Kakwani, specifically $K_{t}=G_{X}-C_{t \mid X}$ and $K_{g}=C_{g \mid X}-G_{X}$, where $K_{t}$ and $K_{g}$ are the Kakwani (1977) indexes of tax and expenditure progressivity (defined as the difference -properly measured-between the concentration of income and the concentration of the fiscal instrument) there is a link between the RS coefficient and the Kakwani coefficients:

$$
R S=\tau \cdot K_{t}+\gamma \cdot K_{g}
$$

where $t$ and $g$ are sizes of taxes and expenditures, respectively, measured as percentage of ex ante income, and $\tau=t /(1-t+g)$ and $\gamma=g /(1-t+g)$ are the corresponding sizes of taxes and expenditures, adjusted by surplus / deficit of the fiscal accounts (see Kakwani, 1977, 1984; Lambert, 1985, 1988; Jenkins, 1988). In the case of balanced budget $(t=g)$,

$$
R S=t \cdot\left(K_{t}+K_{g}\right)
$$

Equation (3) and the balanced-budget version show that, absent reranking, the redistribution effect can be fully decomposed into progressive and size effects of fiscal policy. This decomposition was widely studied by Reynolds and Smolensky (1977), Jenkins (1988) and others at the international level, and by Ahumada et al. (1996) and Cont and Porto $(2014,2016 a, 2016 b)$ in Argentina.

Consider now that income units change places after fiscal policy. Kakwani (1984, 1986) finds that the vertical effect $V^{K}$ overestimates $R E$ when there is reordering. Of course, the same happens with the RS decomposition. The difference between $R E$ and $V^{K}$ in equation (2) is known as the "reranking effect" (Atkinson, 1980; Plotnick, 1981 ) and is caused by the reordering of income units.

It is worth noticing that, throughout the literature, several Gini decompositions involved a residuum. Some authors found it difficult to explain (Mookherjee and Shorrocks, 1982) or explained it partially by reranking (Silber, 1989), or by differences in concentration areas (Bhattacharya and Mahalanobis, 1967), or attached an interpretation of expected value of a game played by individuals (Pyatt, 1976). Aronson, Johnson and Lambert (1994) linked the residuum to the reranking effect introduced by Atkinson and Plotnick. ${ }^{4}$ By construction, the reranking effect $\left(R^{A P}\right.$ $\left.=G_{Y}-C_{Y \mid X}\right)$ is non-negative definite. ${ }^{5}$

4 Other decompositions have been studied in the literature. The research line followed by Duclos (1993) considers an ordering of selected instruments of fiscal policy, for example, $\left\{\mathrm{t}_{1}, \mathrm{t}_{2}, \mathrm{~g}_{1}, \mathrm{~g}_{2}, \mathrm{~g}_{3}\right\}$. The decomposition following an ordering is useful in identifying which tax or expenditure is more important 
Atkinson (1980) argued that changes in the ranking of observations do not affect the degree of inequality in the ex post distribution nor the redistributive effect. Rather, he regarded the reranking as a difference between two measures of redistribution effect $(R E$ and $V$ ). Urban (2009b), taking on Atkinson and Plotnick, clarifies this argument by stating that reranking is a by-product of an income redistribution process; but that it does not contribute, positively or negatively, to the redistributive effect. Moreover, Urban (2009a) shows that reranking of income units does not influence the redistributive effect. In fact, the redistributive effect captures the narrowing of distance between income distributions, and reranking and vertical effects are endogenous results. A summary of the observations by Atkinson and Urban can be put this way: comparing any two distributions of income, $R E$ is the difference of the Gini coefficients attached to both distributions. Given $R E$, if there is more (less) reranking, then there is more (less) vertical effect, and vice-versa. ${ }^{6}$

Finally, before having coined the reranking name, this effect had been referred to as a "horizontal effect" (Kakwani, 1984, 1986) because it seemingly captured the unequal treatment of equals. The horizontal effect was initially measured by Aronson, Johnson and Lambert (1994) and Aronson and Lambert (1994) over distributions that include ex ante exact equals. This way, the authors decomposed vertical and horizontal effects from reranking. The specific relationship is:

$$
R E=V^{A J L}-H^{A J L}-R^{A J L}
$$

In addition, the authors showed that $R^{A P}=R^{A J L}$. Again, the net $V-H$ effect overestimates $R E$ when there is reordering.

On another line of research, Duclos, Jalbert and Araar (2003) decomposed the same effects, using a class of social welfare functions that considers both aversion to

in determining re-ranking. Jenkins (1988) proposes two decompositions to (2), the first one is equal to (3) -see equation (9) of his paper- and the second one being a decomposition into (i) interim distribution of ex ante income minus taxes and (ii) interim distribution of ex ante income plus expenditures (see equation (10) of his paper). However, this alternative approach to measuring fiscal policy effect and reranking cannot be matched to the traditional Kakwani vertical effect of taxes and expenditures so we do not pursue it here.

5 On another hand, both vertical and horizontal effects may have (different) ethic grounds based on welfare theory, while justifications for reranking are not straightforward. Notwithstanding, Schiller (1977), King (1983) and Wagstaff (2009) provide an alternative interpretation that reranking is a good result in that reflects mobility of income units. Wagstaff (2009) discusses this argument in a context of growth and income redistribution (and such interpretation could be difficult to argue in a context of execution of fiscal budgets).

6 Lerman and Yitzhaki (1995) represented the vertical and reranking effects starting from the ex post income distribution. The $R E$ is, in this case, the sum of vertical and reranking effects. Consequently, the decomposition of $R E$ between a vertical effect and reranking effect pivoting on ex ante ordering (as in Kakwani-Atkinson-Plotnick) or pivoting on ex post ordering (as in Lerman and Yitzhaki) is a practical matter, depending on the researcher preference to preserve pre-fiscal or post-fiscal rankings. 
riskiness in net incomes and aversion to rank inequality, and encompasses both Gini and Atkinson coefficients:

$$
R E=V^{D J A}-H^{D J A}-R^{D J A}
$$

According to the authors, $V^{D J A}$ represents the decrease in inequality yielded by a tax which treats equals equally, $H^{D J A}$ measures the increase in overall income inequality attributable to the unequal post-tax treatment of pre-tax equals, and $R$ measures the extent of reranking.

Given that data bases rarely contained exact ex ante income units, van de Ven, Creedy and Lambert (2001) and Urban and Lambert (2008) extended the analysis to groups of ex ante close equals. ${ }^{7}$ Urban and Lambert (2008) also reconsidered the interpretations of vertical, horizontal and reranking effects taking into consideration the possibility of reranking within close equals (WG) and reranking of entire groups (EG). In particular, they show that

$$
R E=V^{U L}-H^{U L}-R^{A P}
$$

where $V^{U L}=V^{A J L}+R^{E G}, H^{U L}=H^{A J L}-R^{W G}$ and $R^{A P}=R^{A J L}+R^{W G}+R^{E G}$.

\section{RERANKING WHEN INDIVIDUAL UNITS BELONG TO MUTUALLY EXCLUSIVE GROUPS}

This section advances further in the decomposition of Gini, and redistribution and reranking effects when population can be meaningfully divided into mutually exclusive groups. In this context, it introduces the main contribution of the paper, which is the measurement of distributive effects of fiscal policy under these conditions (Propositions 1 to 3 ).

Assume now that $\left\{x_{i}\right\}$ is partitioned into $S$ groups of size $N_{S}$, such that individual units within group $s_{j}$ have -not necessarily similar- ex ante income in $\left[x_{S j L}, x_{S j U}\right]$, which possibly overlap with income of individual units within group $s_{k}\left[x_{S k L}, x_{S k U}\right]$. This way, individual units belong to mutually exclusive groups. Relabel $x_{i}$ as $x_{i, s}$ and $y_{i}$ as $y_{i, s}$ (individual $i$, group $s$ ), such that average incomes are $\mu_{X}$ (ex ante average income), $\mu_{X, s}$ (ex ante average income of group $s$ ), $\mu_{Y}$ (ex post average income) and $\mu_{Y, s}($ ex post average income of group $s$ ).

7 They study the case of distributions $\left\{x_{i}\right\}$ that can be partitioned into $s$ groups of size $N_{S}$, such that all individual units within group $s$ have ex ante income $x_{i, s}$ in $\left[x_{S L}, x_{S U}\right]$ and that the lower bound (SL) and upper bound (SU) at group level are such that groups do not overlap. 
With this information, the Gini coefficient can be decomposed as in Bhattacharya and Mahalanobis (1967), Pyatt (1976), Silber (1989), Lambert and Aronson (1993), or Dagum (1997): ${ }^{8}$

$$
G_{X}=G_{X}^{W}+G_{X}^{A}=G_{X}^{W}+G_{X}^{T}+G_{X}^{B}
$$

that is, given the distribution $X=\left\{x_{i}\right\}$, the Gini coefficient of inequality can be additively decomposed into the following effects: inequality within groups $\left(G_{X}{ }^{W}\right)$ and inequality across groups $\left(G_{X}{ }^{A}\right)$, which can be decomposed into inequality due to the possibility that income of units belonging to low-income groups is higher than income of units belonging to high-income groups (this effect is known as overlap or trans-variation; we use the second term: $G_{X}^{T}$ ) and inequality due to difference of mean income between groups $\left(G_{X}^{B}\right)$. After the introduction by Bhattacharya and Mahalanobis (1967) and Pyatt (1976), this decomposition was explored in Argentina by Dieguez and Petrecolla (1978), Porto and Cont (1998). Lambert and Aronson (1993) present a similar decomposition, and identifiy a residuum as the overlapping effect of income units from different groups. Dagum (1997) suggests a similar decomposition as in Pyatt (1976) and defines the transvariation effect.

Monti et al. (2012) use the later definition to decompose the reranking effect when income distributions can be partitioned in groups. This way, reranking can be adapted to the case with groups which may overlap before and after taxes. Specifically, the authors show that

Result 1 (Monti et al., 2012). The concentration index of ex post income (given ex ante ordering) $C_{Y \mid X}$ can be decomposed into

$$
C_{Y \mid X}=C_{Y \mid X}^{W}+C_{Y \mid X}^{A}=C_{Y \mid X}^{W}+C_{Y \mid X}^{T}+C_{Y \mid X}^{B}
$$

The reranking effect, defined in equation (2) as $R^{A P}=G_{Y}-C_{Y \mid X}$, is decomposed as

$$
R^{A P}=G_{Y}^{W}+G_{Y}^{A}-C_{Y \mid X}^{W}-C_{Y \mid X}^{A}=R^{W}+R^{A}
$$

In other words, the reranking effect can be decomposed into within-group reordering (i.e., how much of the reordering is taking place between income units belonging to the same group) and across-group reordering (i.e., how much reordering is taking place between richer units in poor groups vs. poorer units in rich groups). Finally, although the decomposition of across-group reranking $\left(R^{A}\right)$ into an overlapping

8 In two separate works, Monti (2007) and Griffiths (2008) show that the traditional measures (Pyatt, Silber) and newer measures (Dagum) are all identical. 
/ transvariation component $\left(R^{T}=G_{Y}^{T}-C_{Y \mid X}^{T}\right)$ and a between-group component $\left(R^{B}=G_{Y}^{B}-C_{Y \mid X}^{B}\right)$ is mathematically feasible, the authors argue that they are not proper measures of reranking.

The following propositions show that the same equality holds for concentration coefficients of any variable (say, $t$ or $g$ ) preserving the ordering $X$, which allows us to decompose concentration curves, vertical effect, Kakwany and Reynolds-Smolensky coefficients in the presence of mutually exclusive groups.

Proposition 1: Assume that individuals are pooled in $S$ mutually exclusive groups Consider that individuals identified by a pair of variables $(X, Z)$ and are ordered according to variable $X$ (first, increasing order of average $x$ among groups; second, increasing order of individual $x$ within groups). The concentration coefficient of variable $Z$, given the partition into $s$ groups and the ordering $X$, can be decomposed into:

$$
C_{Z \mid X}=C_{Z \mid X}^{W}+C_{Z \mid X}^{A}=C_{Z \mid X}^{W}+C_{Z \mid X}^{T}+C_{Z \mid X}^{B}
$$

Proof: see Appendix A.3.

Proposition 1 is helpful to decompose the Vertical / Reynolds Smolesnky coefficient in the presence of groups. The first result is summarized in

Proposition 2: Assume that individuals are pooled in $S$ mutually exclusive groups. Consider that are individuals identified by a pair of variables $(X, Y)$, where $X$ is ex ante income and $Y$ is ex post income, and are ordered according to variable $X$ (first, increasing order of average $x$ among groups; second, increasing order of individual $x$ within groups). Then the Vertical Effect can be decomposed into within and across (and also into between and transvariation) effects:

$$
V=V^{W}+V^{A}=V^{W}+V^{T}+V^{B}
$$

The proof is straightforward.

Next proposition shows that Kakwani coefficients and tax and expenditure effects of the Vertical / Reynolds Smolensky coefficient (equation (3)) can be further decomposed in the presence of groups.

Proposition 3: Assume that individuals are pooled in $S$ mutually exclusive groups, and are ordered according to variable X (first, increasing order of average x among groups; second, increasing order of individual $x$ within groups). The Kakwani coefficients for expenditures and taxes can be decomposed as

$$
K_{Z}=K_{Z}^{W}+K_{Z}^{A}=K_{Z}^{W}+K_{Z}^{T}+K_{Z}^{B}
$$

where $K_{Z}^{A}=K_{Z}^{T}+K_{Z}^{B}$, for $z=t, g$. 
The vertical / Reynolds Smolensky effect can be decomposed as

$$
\begin{aligned}
R S & =\tau \cdot\left(K_{t}^{W}+K_{t}^{T}+K_{t}^{B}\right)+\gamma \cdot\left(K_{g}^{W}+K_{g}^{T}+K_{g}^{B}\right) \\
& =R S^{W}+R S^{T}+R S^{B}
\end{aligned}
$$

where $R S^{l}=\tau \cdot K_{t}^{l}+\gamma \cdot K_{g}^{l}$, for $l=W, T, B$, and $R S^{A}=R S^{T}+R S^{B}$.

This way, in the case with groups which may overlap before and after taxes we can get a wider picture of the effects of fiscal policy on redistribution, by shedding light on the impact of expenditures and taxes. Do they affects individuals of a specific group or they affect all population? What is more important, the size of the taxes or expenditures across groups or, whether they are progressive / regressive among such groups?

In the following sections we apply Propositions 1 to 3 to the case of Argentina, in order to show how the decomposition works. This way we disentangle the redistributive effect of fiscal policy shown in Cont and Porto (2016a, 2017).

\section{APPLICATION: THE CASE OF ARGENTINA}

\subsection{Context}

Argentina is a country located in South America. Average per capita income exceeded US\$ 9,000 in 2010. This average, however, hides large regional disparities, with provincial incomes ranging from US\$27,508 in the city of Buenos Aires to US\$ 3,781 in the province of Santiago del Estero. Such disparities also hold for other social indicators (Unsatisfied Basic Needs, for example), although other indicators may show less provincial heterogeneity (Human Development Index). Table B1 in Appendix B contains detailed information and explanations on these indicators.

In a related research agenda, we developed a database of personal and regional distribution of income, the execution of fiscal policy (consolidating national and provincial budgets), and an allocation of expenditure benefits and tax incidence on different units of income (quintiles at a provincial level) for Argentina between 1995 and 2010. With this database, answered several questions on the effects of fiscal policy on income distribution (Cont and Porto (2014, 2016a, 2016b and 2017) for the whole period or selected years. In this paper we select 2010 as the year of analysis, which is characterized by growth, decreasing inequality and balanced fiscal accounts. 
The consolidated nation-provinces expenditure and revenues represented about 40 percent of GDP in $2010 .{ }^{9,10}$ We analyze the redistributive effect of public budget following two approaches. The first one through the national-provincial channels. This approach is relevant because provinces are responsible for the execution of 45 percent of consolidate expenditure, and the collection of 22 percent of taxes. Redistribution among provinces works through tax sharing (Coparticipation) rules, national expenditure and transfers by the national government. Redistribution among individuals works through expenditure benefits and tax incidence. The second approach is through cash-in kind expenditure channels. Cash transfers are public expenditures that go directly to individuals in cash (social security, social programs, etc.), and constitute a source of interim income (usually, the income declared in household surveys). In kind expenditures are public expenditures that benefit individuals through the services they render (education, health, some public subsidies to sustain lower prices of certain services -mainly transport and energy-, etc.). This approach is interesting because literature has discussed the effects of approaching beneficiaries through cash instruments rather than standard public goods. ${ }^{11}$ Expenditure in the form of cash transfers represented 32 percent of total expenditure in 2010.

\subsection{Aggregate measures for Argentina 2010}

As an illustration the execution of the fiscal policy for Argentina in 2010 is used. This year is the last with full information for the consolidated nation-provinces expenditures, taxes and transfers, measured according to their economic effects, i.e., benefit of expenditures and incidence of taxes. Under a definition of personal distribution of income, units are quintiles within a province (5 quintiles x 24 provincial jurisdictions: 23 provinces and the City of Buenos Aires). Under a definition of regional distribution of income, units are provincial jurisdictions.

The left panel of Table 1 summarizes that, under a definition of personal distribution of income, starting from an initial level of 0.512 (Gini coefficient of inequality) the redistributive effect of fiscal policy (RE) was 0.098 , or 19 percent of ex ante Gini.

Table 1 also presents the decomposition of the RE effect between the vertical / Reynolds-Smolensky effect $(\mathrm{V})$ and reranking $(\mathrm{R})$. In the personal dimension the vertical effect was 0.102 and the reranking effect represented 4 percent of personal

9 The research project referred to in the text was done using national accounts with base 1993. In 2014 the Argentine government changed the base year of national accounts to 2004. The consolidated expenditure represented 40 percent of GDP in 2010 with the 1993 accounts, and almost 30 percent of GDP with the new accounts. The public sector continued growing in Argentina to peak 42.5 percent of the GDP in 2015 (new accounts).

10 Municipal budgets are excluded because detailed information is unavailable. They represent around 8 percent of total expenditure in Argentina. Nonetheless, they are partially considered in the analysis through the transfers from provinces to municipalities (which represent about half of municipal expenditures).

11 See, for example, Gimpelson and Treisman (2002), and Calvo and Murillo (2004). 
RE. Even though reranking may seem low, it is in line with effects estimated by the literature. For example, Aronson and Lambert (1994, p. 291) estimate a 5 percent reranking effect in British tax policy (based on fiscal data of the United Kingdom family expenditure survey). The same authors refer to data from Marenzi (1993) to find a 1.8 percent reranking effect in Italy tax policy. Urban and Lambert (2008) estimate a 12 percent reranking effect caused by direct taxes in Croatia for year 2003. Monti et al. (2012) estimate a 5.7 percent reranking effect caused by taxes and government transfers in the US for year 2007. Curiously, Kim and Lambert (2007) estimated a 36 percent reranking effect caused by a broad definition of fiscal policy in US for year 2004. Duclos, Jalbert and Araar (2003) present an illustration of a measure that combines the Gini and Atkinson coefficients for Canada in 1981-1995 and find erosion due to horizontal inequality and reranking of about 15 to 21 percent of the net redistributive effect.

The right panel of Table 1 summarizes that, under a regional definition of income distribution, starting from an initial level of 0.267 , RE was 0.032 , or 12 percent of ex ante Gini. The vertical effect was 0.036 and the reranking represented 10 percent of regional RE. This effect is calculated ordering provinces by per capita income and is found significant. ${ }^{12}$ Porto (2017) shows that reranking is much stronger if the initial ranking is based on the provincial revenues (as in Germany).

A final observation from Table 1 is that, under both definitions of income distribution (personal and regional), there is a partial compensation of the vertical $\mathrm{V}$ effect as fiscal policy in Argentina creates reranking of income units (individualsquintiles / provinces). The reranking effect is stronger on the regional dimension than on the personal dimension.

Table 2 presents the Reynolds-Smolensky (vertical) coefficient for personal and regional distribution of income, following the two approaches of national-provincial budgets and cash-in kind expenditures motivated above.

Consider first the personal dimension of income distribution. Under a decomposition of fiscal budget between national and provincial levels, column (I) in Table 2 shows that provincial expenditure is highly progressive and represent 40 percent of consolidated expenditure, followed by national expenditure (60 percent of consolidated). Taxes are regressive, but national taxes have stronger redistributive effect as they represent 78 percent of consolidated (national - provincial) revenues. Under a decomposition

12 Cont and Porto $(2016 \mathrm{~b}, 2017)$ provide more details and shows that many provinces benefit from redistribution, but to different degrees. For example, poor provinces like Formosa, La Rioja or Santiago del Estero scale several positions in the ranking based on ex post income, while other provinces that also benefit from redistribution scale less (Catamarca, Río Negro or Jujuy) or even lose positions (Salta, Corrientes or Tucumán). The province of Buenos Aires contributes to redistribution and loses positions, while the city of Buenos Aires also contributes to redistribution but keeps separated from the rest of the jurisdictions. 


\section{TABLE 1}

ARGENTINA 2010. GINI EX ANTE $\left(\mathrm{G}_{\mathrm{X}}\right)$ AND EX POST $\left(\mathrm{G}_{\mathrm{Y}}\right)$, CONCENTRATION INDEX OF EX POST INCOME ( $\left.\mathrm{C}_{Y \mid X}\right)$, REDISTRIBUTION EFFECT (RE) AND DECOMPOSITION BETWEEN VERTICAL (V) AND RERANKING (R) EFFECTS

\begin{tabular}{|l|c|c|}
\hline & Personal & Regional \\
\hline $\mathrm{G}_{\mathrm{X}}$ & 0.512 & 0.267 \\
$\mathrm{C}_{\mathrm{YlX}}$ & 0.410 & 0.231 \\
$\mathrm{G}_{\mathrm{Y}}$ & 0.414 & 0.235 \\
$\mathrm{RE}$ & 0.098 & 0.032 \\
$\mathrm{~V}(\mathrm{RS})$ & 0.102 & 0.036 \\
$\mathrm{R}$ & 0.004 & 0.003 \\
$\mathrm{R} / \mathrm{RE}$ & $4.0 \%$ & $10.1 \%$ \\
\hline
\end{tabular}

Notes: $\mathrm{RE}=\mathrm{V}-\mathrm{R}$.

Source: National aggregates based on provincial data from Cont and Porto (2016b, 2017).

TABLE 2

ARGENTINA 2010. DECOMPOSITION OF THE VERTICAL - REYNOLDS SMOLENSKY EFFECT: NATIONAL - PROVINCIAL BUDGETS; CASH-IN KIND EXPENDITURES

\begin{tabular}{|l|c|c|c|c|c|}
\hline \multicolumn{3}{|c|}{$\begin{array}{c}\text { National - Provincial } \\
\text { decomposition of RS }\end{array}$} & \multicolumn{3}{c|}{$\begin{array}{c}\text { Cash-In Kind } \\
\text { decomposition of RS }\end{array}$} \\
\hline & Personal & Regional & & Personal & Regional \\
\hline & $(\mathrm{I})$ & $(\mathrm{II})$ & & $(\mathrm{III})$ & $(\mathrm{IV})$ \\
$\tau_{\mathrm{N}}$ & 0.303 & 0.303 & $\tau_{\times \mathrm{C}}$ & 0.104 & 0.104 \\
$\mathrm{~K}_{\mathrm{tN}}$ & -0.122 & -0.156 & $\mathrm{~K}_{\mathrm{t} \times \mathrm{C}}$ & -0.062 & -0.209 \\
$\tau_{\mathrm{P}}$ & 0.084 & 0.084 & $\tau_{\times \mathrm{XE}}$ & 0.283 & 0.283 \\
$\mathrm{~K}_{\mathrm{tP}}$ & -0.115 & -0.046 & $\mathrm{~K}_{\mathrm{t} \times \mathrm{E}}$ & -0.142 & -0.104 \\
$\gamma_{\mathrm{N}}$ & 0.212 & 0.212 & $\gamma_{\mathrm{C}}$ & 0.122 & 0.122 \\
$\mathrm{~K}_{\mathrm{gN}}$ & 0.250 & 0.196 & $\mathrm{~K}_{\mathrm{gC}}$ & 0.326 & 0.224 \\
$\gamma_{\mathrm{P}}$ & 0.176 & 0.176 & $\gamma_{\mathrm{E}}$ & 0.265 & 0.265 \\
$\mathrm{~K}_{\mathrm{gP}}$ & 0.543 & 0.256 & $\mathrm{~K}_{\mathrm{gE}}$ & 0.409 & 0.223 \\
$\mathrm{~V}(\mathrm{RS})$ & 0.102 & 0.036 & $\mathrm{~V}(\mathrm{RS})$ & 0.102 & 0.036 \\
\hline
\end{tabular}

Notes: The definition of $\left(\mathrm{K}_{\mathrm{t}}, \tau, \mathrm{K}_{\mathrm{g}}, \gamma\right)$ is done in equation (3). In this table we apply it to the division of National and Provincial budgets (subscript $\mathrm{N}$ and P, correspondingly) and to Cash-In Kind expenditures (subscript $\mathrm{C}$ and $\mathrm{E}$, correspondingly). The results on redistribution of personal income reported in this table are consistent with those reported in Cont and Porto (2016a) for a different definition of income units. 
of fiscal budget between cash transfers and in-kind expenditures, ${ }^{13}$ column (III) in Table 2 shows that in-kind expenditure is the most redistributive tool, followed by cash expenditures. As expected, $t_{\times E}$ is more regressive than $t_{\times C}$, and also weighs more in a country where indirect taxation takes a high share -73 percent- of total taxes.

Table 2 also decomposes the Reynolds-Smolensky (vertical) effect for regional distribution of income. Under a decomposition of fiscal budget between national and provincial levels, column (II) in Table 2 shows that expenditure is less progressive and national taxes are more regressive when the effects are calculated over 24 provincial jurisdictions rather than 120 income units (quintil-provinces). On the other hand, provincial taxes are less regressive. These results are reasonable from an aggregate point of view: treating all quintiles in a province equally in a regional comparison, provincial expenditures (which are the main progressive tool to explain the redistribution effect) are less progressive and also provincial taxes are less regressive, when analyzed under a regional definition of income. Overall, the redistributive effect is lower at the regional level, mainly because of the reduced progressive effect of provincial expenditures (provided that sizes are the same under both definitions of income distribution). This result is also found for the progressive effect of in-kind expenditures at a regional level (column IV in Table 2).

\section{REDISTRIBUTION AND RERANKING EFFECTS UNDER DIFFERENT GROUPS}

In this section we apply the new methodology to a specific pooling of provinces into mutually exclusive groups, in order to show the contribution of Propositions 1 to 3 to the analysis of redistributive effect of fiscal policy.

We classify provinces into four groups according to their socio-economic levels, following Nuñez Miñana (1972). The socio-economic classification process is based on population, population dispersion and development gap measured with quality of human resources, quality of housing and automobiles per inhabitant. The four groups are denominated Advanced, Low Density, Intermediate and Lagged. Using the terminology of Section 2, $S=4$, and each $s$ includes individual units depending on the number of provinces in each group: the Advanced group consists of 5 provinces (25 quintiles), the Low-Density group consists of 6 provinces (30 quintiles), the Intermediate group consists of 5 provinces ( 25 quintiles), and the Lagged group

13 In the cash-in kind decomposition of budget, taxes related to cash transfers ( $\mathrm{t}_{\times \mathrm{C}}$ in Table 2) are taxes paid by economic agents at the time of receiving their income (mostly, labor and income taxes). Taxes related to in kind expenditures $\left(\mathrm{t}_{\mathrm{xE}}\right.$ in Table 2) are taxes collected after agents receive their income (consumption taxes, property taxes, etc.). Although there is a high correlation between direct taxes and $\mathrm{t}_{\times \mathrm{C}}$, and between indirect taxes and $\mathrm{t}_{\times \mathrm{E}}$, they are not strictly the same. 
consists of 8 provinces (40 quintiles). ${ }^{14}$ Figure 1 depicts the Argentine provinces according to this classification. ${ }^{15}$

\section{FIGURE 1}

\section{GROUPS OF PROVINCES ACCORDING TO DEVELOPMENT LEVEL}

Advanced, Low Density, Intermediate and Lagged Provinces

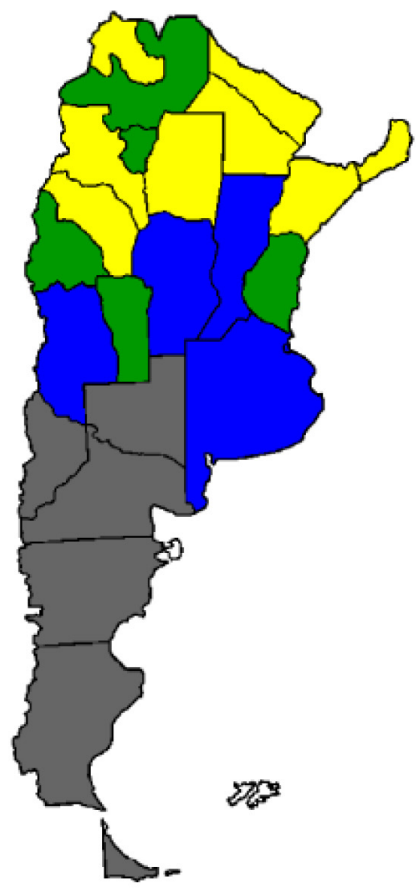

Source: Table B1 and footnote 14. Blue: Advanced; Grey: Low Density; Green: Intermediate; Yellow: Lagged.

14 The group of Advanced Jurisdictions includes the city of Buenos Aires, and the provinces of Buenos Aires, Córdoba, Mendoza and Santa Fe. The group of Intermediate Jurisdictions comprises Entre Ríos, Salta, San Juan, San Luis and Tucumán. The group of Low Density Jurisdictions includes Chubut, La Pampa, Neuquén, Río Negro, Santa Cruz and Tierra del Fuego. The group of Lagged Jurisdictions comprises Catamarca, Chaco, Corrientes, Formosa, Jujuy, La Rioja, Misiones and Santiago del Estero.

15 The methodology can be applied to different criteria to form groups, provided a properly the selection has economic interests. For example, given the federal nature of fiscal policy in Argentina, there is a regional redistribution among beneficiary provinces and contributing ones through the revenue sharing (coparticipation) rules. It may be of interest to classify provinces into two groups $(\mathrm{S}=2)$ and to study the redistributive effect of fiscal policy by understanding the within, between and transvariation effects between those two groups. This analysis is available to the reader upon request. 
The level of activity is concentrated in the Advanced Group (78 percent of GDP in 5 provincial jurisdictions, for an area that represents 27 percent of the total surface and includes 66 percent of population). On the other end, the 8 provinces of the Lagged group cover 24 percent of the surface, holds 15 percent of population but contributes to 7 percent of the GDP (see details in Table B1 in Apendix B).

Tables 3 and 4 show the decomposition of the Gini, concentration, progressiveness and redistribution indexes within-groups and across-groups (and also between groups and overlapping of income units from different groups) for the definition of personal distribution of income.

\section{TABLE 3}

ARGENTINA 2010. DECOMPOSITION OF RE, V AND R INTO WITHIN, BETWEEN AND TRANSVARIATION COMPONENTS. PERSONAL DISTRIBUTION OF INCOME

\begin{tabular}{|l|c|c|c|c|c|c|c|}
\hline $\mathrm{G}_{\mathrm{X}}$ & 0.512 & $\mathrm{C}_{\mathrm{YIX}}$ & 0.410 & & $\mathrm{G}_{\mathrm{Y}}$ & 0.414 & \\
$\mathrm{G}^{\mathrm{W}} \mathrm{X}$ & 0.263 & $\mathrm{C}^{\mathrm{W}} \mathrm{YIX}$ & 0.213 & & $\mathrm{G}_{\mathrm{Y}}^{\mathrm{W}}$ & 0.215 & \\
$\mathrm{G}_{\mathrm{X}}^{\mathrm{A}}$ & 0.248 & $\mathrm{C}^{\mathrm{A}} \mathrm{YIX}^{\mathrm{T}}$ & 0.197 & & $\mathrm{G}_{\mathrm{Y}}^{\mathrm{A}}$ & 0.199 & \\
$\mathrm{G}_{\mathrm{X}}^{\mathrm{T}}$ & 0.114 & $\mathrm{C}^{\mathrm{T}} \mathrm{YIX}$ & 0.088 & & $\mathrm{G}_{\mathrm{Y}}^{\mathrm{T}}$ & 0.089 & \\
$\mathrm{G}^{\mathrm{B}} \mathrm{X}$ & 0.134 & $\mathrm{C}^{\mathrm{B}}{ }_{\mathrm{YIX}}$ & 0.109 & & $\mathrm{G}_{\mathrm{Y}}^{\mathrm{B}}$ & 0.110 & \\
& & & & & $\mathrm{RE}$ & 0.098 & \\
& & $\mathrm{~V}$ & 0.102 & & $\mathrm{R}$ & 0.004 & \\
& & $\mathrm{~V}^{\mathrm{W}}$ & 0.051 & $50 \%$ & $\mathrm{R}^{\mathrm{W}}$ & 0.002 & $51 \%$ \\
& & $\mathrm{~V}^{\mathrm{A}}$ & 0.051 & $50 \%$ & $\mathrm{R}^{\mathrm{A}}$ & 0.002 & $49 \%$ \\
& & $\mathrm{~V}^{\mathrm{T}}$ & 0.026 & $25 \%$ & & & \\
& & $\mathrm{~V}^{\mathrm{B}}$ & 0.026 & $25 \%$ & & & \\
\hline
\end{tabular}

Notes: G: Gini; C: concentration index; V: vertical effect; RE: redistributive effect; R: reranking effect. Superscripts W: within groups, A: across groups, T: transvariation or overlapp, B: between or average income among groups. Subscripts X: ex ante; Y|X: ex post income with ex ante ordering; Y: ex post income with ex post ordering.

Ex ante income inequality in year $2010\left(G_{X}=0.512\right)$ is evenly distributed between within-group inequality (0.263) and across-group inequality (0.248). Moreover, across-group inequality is explained by differences in groups' average income (54 percent: 0.134 out of 0.248 ) and income overlapping of units belonging to different groups (46 percent: 0.114 out of 0.248 ).

The redistribution effect of consolidated fiscal policy is 0.098 in that year, reducing the Gini coefficient to 0.414 . $R E$ is the net result of a vertical effect $(V=0.102)$ partially compensated by reranking $(R=0.004)$. The quantification of equations $(5)-(6)$ to the four-group classification shows the interesting result that both the vertical a reranking effects are also evenly distributed between within-group and across-groups effects 
( $V^{W}=V^{A}$, and $R^{W}=R^{A}$, respectively) and that the redistributive vertical effect across groups also distributes evenly between reduction of average incomes and reduction of income overlaps $\left(V^{T}=V^{B}\right)$.

Table 4 further explores the vertical / Reynolds-Smolensky effect for the nationalprovincial and the cash-in kind decomposition of consolidated budget. In the case of national-provincial decomposition of the consolidated budget, provincial expenditure is identified as the most progressive tool for income redistribution $\left(K_{g P}=0,543\right)$. The within-group effect of $K_{g P}$ is very important, as it should be expected from a redistributive provincial tool (53 percent of 0.543 ), but there is also a side-effect in the reduction of overlapping (28 percent of 0.543 ) meaning that poor income units in high-income groups receive significantly more provincial expenditure than rich income units from low-income groups. This is a plausible result: provinces are engaged in redistribution within their own jurisdictions and allocate resources to lower quintiles (including provinces with high income). Moreover, about 19 percent of the progressive effect corresponds to a reduction of disparities between groups, as provinces with lower average income (say, Intermediate and Lagged) engage in higher levels of provincial expenditure than provinces with higher average income (mainly, the Advanced group). ${ }^{16}$

\section{TABLE 4}

ARGENTINA 2010. DECOMPOSITION OF THE VERTICAL - REYNOLDS SMOLENSKY EFFECT INTO WITHIN, BETWEEN AND TRANSVARIATION COMPONENTS. PERSONAL DISTRIBUTION OF INCOME

\begin{tabular}{|l|c|c|c|c|c|c|c|c|c|}
\hline \multicolumn{3}{|c|}{ National - Provincial decomposition of RS } & \multicolumn{5}{c|}{ Cash-In Kind decomposition of RS } \\
\hline & Full & $\mathrm{W}$ & $\mathrm{T}$ & $\mathrm{B}$ & & Full & $\mathrm{W}$ & $\mathrm{T}$ & $\mathrm{B}$ \\
\hline$\tau_{\mathrm{N}}$ & 0.303 & & & & $\tau_{\times \mathrm{C}}$ & 0.104 & & & \\
$\mathrm{~K}_{\mathrm{tN}}$ & -0.122 & -0.069 & 0.008 & -0.060 & $\mathrm{~K}_{\mathrm{t} \times \mathrm{C}}$ & -0.062 & -0.047 & 0.060 & -0.074 \\
$\tau_{\mathrm{P}}$ & 0.084 & & & & $\begin{array}{c}\tau_{\times \mathrm{E}} \\
0.283\end{array}$ & & & \\
$\mathrm{~K}_{\mathrm{tP}}$ & -0.115 & -0.086 & -0.086 & 0.057 & $\mathrm{~K}_{\mathrm{t} \times \mathrm{E}}$ & -0.142 & -0.082 & -0.039 & -0.020 \\
$\gamma_{\mathrm{N}}$ & 0.212 & & & & $\gamma_{\mathrm{C}}$ & 0.122 & & & \\
$\mathrm{~K}_{\mathrm{gN}}$ & 0.250 & 0.133 & 0.017 & 0.100 & $\mathrm{~K}_{\mathrm{gC}}$ & 0.326 & 0.178 & 0.045 & 0.104 \\
$\gamma_{\mathrm{P}}$ & 0.176 & & & & $\gamma_{\mathrm{E}}$ & 0.265 & & & \\
$\mathrm{~K}_{\mathrm{gP}}$ & 0.543 & 0.288 & 0.152 & 0.103 & $\mathrm{~K}_{\mathrm{gE}}$ & 0.409 & 0.215 & 0.094 & 0.100 \\
$\mathrm{~V}(\mathrm{RS})$ & 0.102 & 0.051 & 0.026 & 0.026 & $\mathrm{~V}(\mathrm{RS})$ & 0.102 & 0.051 & 0.026 & 0.026 \\
\hline
\end{tabular}

Notes: The definition of $(\mathrm{Kt}, \tau, \mathrm{Kg}, \gamma)$ is done in equation (3). In this table we apply it to the division of National and Provincial budgets (subscript N and P, correspondingly) and to Cash-In Kind expenditures (subscript $\mathrm{C}$ and $\mathrm{E}$, correspondingly).

16 Provinces in the Low Density group, by the mere reason of having low population, display higher per-capita expenditures that provinces in Intermediate and Lagged group. But, on the other hand, their relative weight compared to other groups is low. 
National expenditures are also progressive $\left(K_{g N}=0.250\right.$ in Table 4$)$. Inasmuch redistributing income, the qualitative effects are like those of provincial expenditures. But the composition of national expenditure is balanced between progressiveness within groups and between groups. National taxes are regressive $\left(K_{t N}=-0.122\right.$ in Table 4) with main effect within groups and between groups. There is no significant overlapping effect from national taxes and expenditures.

Provincial taxes are regressive (and have little redistributive effect because of size). However, the decomposition from equation (7) unravels certain aspects of provincial taxation that were unknown so far. On the one hand, the magnitude of the regressive transvariation effect is like that of the within-group effect. In this case, poor income units in high-income groups pay more provincial taxes than rich income units from low-income groups (increasing overlaps). On the other hand, the impact of provincial taxes is progressive between groups, partially counterbalancing the net regressive effect.

In the case of cash-in kind decomposition of the consolidated budget the in-kind expenditure is identified as the most progressive tool for income redistribution $\left(K_{g E}\right.$ $=0.409)$ followed by cash-transfers $\left(K_{g E}=0.326\right)$. In both cases, within-group effect represents over 50 percent of de progressive effect, respectively. However, they have different progressive effect across groups: in the case of in-kind (cash) expenditure the between-group effect represents 24 percent ( 32 percent), while the transvariation effect represents 23 percent (14 percent), of the progressive effect. The overlapping effect of cash transfers is low $(0,045)$ as the benefit received by income units belonging to different groups do not cause significant relative changes in ranking.

Taxes collected ex ante $\left(t_{\times C}\right)$ also show interesting effects: they are regressive $\left(K_{t \times C}\right.$ $=-0.062)$, with a higher within effect $(-0.047)$ than across $(-0.015)$ effect. However, the latter effect hides a strong regressive between-effect (-0.074) partially compensated by an overlapping effect (0.060). On the one hand, high income groups contribute less to such taxes, in average; on the other hand, high income units belonging to poorer groups contribute more taxes than low income units belonging to richer groups (reducing overlapping). Finally, taxes collected after individuals receive their income $\left(t_{\times E}\right)$ are regressive in all dimensions.

Next, we analyze the redistributive effect of consolidated fiscal policy for a distribution of income across provinces. Tables 5 and 6 show the decomposition of the Gini, concentration, progressiveness and redistribution indexes within-groups and across-groups (and also between groups and overlapping among groups) for the definition of regional income distribution.

Ex ante income inequality $\left(G_{X}=0.267\right)$ can be decomposed between withingroup inequality (0.110) and across-group inequality (0.157). Moreover, across-group inequality is mostly explained by differences in average income among different groups (85 percent: 0.134 out of 0.157 ) and little by income overlapping of units belonging to different groups (15 percent: 0.023 out of 0.157 ). The redistribution effect of consolidated fiscal policy is 0.032 , reducing the Gini coefficient to 0.235 . $R E$ is the net result of a vertical effect $(V=0.036)$ partially compensated by reranking 


\section{TABLE 5}

\section{ARGENTINA 2010. DECOMPOSITION OF RE, V AND R INTO WITHIN, BETWEEN AND TRANSVARIATION COMPONENTS. REGIONAL DISTRIBUTION OF INCOME}

\begin{tabular}{|l|c|c|c|c|c|c|c|}
\hline $\mathrm{G}_{\mathrm{X}}$ & 0.267 & $\mathrm{C}_{\mathrm{YIX}}$ & 0.231 & & $\mathrm{G}_{\mathrm{Y}}$ & 0.235 & \\
$\mathrm{G}^{\mathrm{W}} \mathrm{X}$ & 0.110 & $\mathrm{C}_{\mathrm{YIX}}^{\mathrm{C}}$ & 0.104 & & $\mathrm{G}_{\mathrm{Y}}$ & 0.105 & \\
$\mathrm{G}_{\mathrm{X}}^{\mathrm{A}}$ & 0.157 & $\mathrm{C}_{\mathrm{YIX}}^{\mathrm{A}}$ & 0.127 & & $\mathrm{G}_{\mathrm{Y}}^{\mathrm{A}}$ & 0.130 & \\
$\mathrm{G}^{\mathrm{T}} \mathrm{X}$ & 0.023 & $\mathrm{C}^{\mathrm{T}} \mathrm{YIX}$ & 0.018 & & $\mathrm{G}_{\mathrm{Y}}^{\mathrm{T}}$ & 0.020 & \\
$\mathrm{G}_{\mathrm{X}}^{\mathrm{B}}$ & 0.134 & $\mathrm{C}_{\mathrm{YIX}}^{\mathrm{B}}$ & 0.109 & & $\mathrm{G}_{\mathrm{Y}}^{\mathrm{B}}$ & 0.110 & \\
& & & & & $\mathrm{RE}$ & 0.032 & \\
& & $\mathrm{~V}$ & 0.036 & & $\mathrm{R}$ & 0.003 & \\
& & $\mathrm{~V}^{\mathrm{W}}$ & 0.005 & $15 \%$ & $\mathrm{R}^{\mathrm{W}}$ & 0.000 & $9 \%$ \\
& & $\mathrm{~V}^{\mathrm{A}}$ & 0.030 & $85 \%$ & $\mathrm{R}^{\mathrm{A}}$ & 0.003 & $91 \%$ \\
& & $\mathrm{~V}^{\mathrm{T}}$ & 0.005 & $13 \%$ & & & \\
& & $\mathrm{~V}^{\mathrm{B}}$ & 0.026 & $72 \%$ & & & \\
\hline
\end{tabular}

Notes: G. Gini; C: concentration index; V: vertical effect; RE: redistributive effect; R: reranking effect. Superscripts W: within groups, A: across groups, T: transvariation or overlapp, B: between or average income among groups. Subscripts X: ex ante; $\mathrm{YIX}$ : ex post income with ex ante ordering; Y: ex post income with ex post ordering.

\section{TABLE 6}

ARGENTINA 2010. DECOMPOSITION OF THE VERTICAL - REYNOLDS SMOLENSKY EFFECT INTO WITHIN, BETWEEN AND TRANSVARIATION COMPONENTS. REGIONAL DISTRIBUTION OF INCOME

\begin{tabular}{|l|c|c|c|c|c|c|c|c|c|}
\hline \multicolumn{3}{|c|}{ National - Provincial decomposition of RS } & \multicolumn{5}{c|}{ Cash-In Kind decomposition of RS } \\
\hline & Full & $\mathrm{W}$ & $\mathrm{T}$ & $\mathrm{B}$ & & Full & $\mathrm{W}$ & $\mathrm{T}$ & $\mathrm{B}$ \\
\hline$\tau_{\mathrm{N}}$ & 0.303 & & & & $\tau_{\times \mathrm{C}}$ & 0.104 & & & \\
$\mathrm{~K}_{\mathrm{tN}}$ & -0.156 & -0.076 & -0.019 & -0.060 & $\mathrm{~K}_{\mathrm{t} \times \mathrm{C}}$ & -0.209 & -0.108 & -0.027 & -0.074 \\
$\tau_{\mathrm{P}}$ & 0.084 & & & & $\tau_{\times \mathrm{E}}$ & 0.283 & & & \\
$\mathrm{~K}_{\mathrm{tP}}$ & -0.046 & -0.063 & -0.040 & 0.057 & $\mathrm{~K}_{\mathrm{t} \times \mathrm{E}}$ & -0.104 & -0.061 & -0.023 & -0.020 \\
$\gamma_{\mathrm{N}}$ & 0.212 & & & & $\gamma_{\mathrm{C}}$ & 0.122 & & & \\
$\mathrm{~K}_{\mathrm{gN}}$ & 0.196 & 0.072 & 0.025 & 0.100 & $\mathrm{~K}_{\mathrm{gC}}$ & 0.224 & 0.091 & 0.029 & 0.104 \\
$\gamma_{\mathrm{P}}$ & 0.176 & & & & $\gamma_{\mathrm{E}}$ & 0.265 & & & \\
$\mathrm{~K}_{\mathrm{gP}}$ & 0.256 & 0.105 & 0.049 & 0.103 & $\mathrm{~K}_{\mathrm{gE}}$ & 0.223 & 0.085 & 0.039 & 0.100 \\
$\mathrm{~V}(\mathrm{RS})$ & 0.036 & 0.005 & 0.005 & 0.026 & $\mathrm{~V}(\mathrm{RS})$ & 0.036 & 0.005 & 0.005 & 0.026 \\
\hline
\end{tabular}

Notes: The definition of $(\mathrm{Kt}, \tau, \mathrm{Kg}, \gamma)$ is done in equation (3). In this table we apply it to the division of National and Provincial budgets (subscript N and P, correspondingly) and to Cash-In Kind expenditures (subscript $\mathrm{C}$ and $\mathrm{E}$, correspondingly). 
$(R=0.003)$. From quantification of equations (5)-(6), we find that changes in average incomes between groups represent 72 percent of the across groups vertical effect. Also, the reranking effect is mostly explained by narrowing of differences across groups (91 percent). In both measures, within-group effects are small.

Table 6 further explores the vertical / Reynolds-Smolensky effect for the nationalprovincial and the cash-in kind decomposition of consolidated budget. Qualitative results are similar to those discussed for personal distribution of income. We highlight here that within-group effects of both national and provincial expenditures are lower than, and between-group effects are equal to, those obtained for the personal definition of income distribution.

In the case of cash-in kind decomposition, the overlapping effect of ex ante taxes $\left(t_{\times C}\right)$ is regressive (it was positive in the case of personal distribution of income). Richer provinces in poorer groups contribute relatively less to ex ante taxes.

\section{CONCLUSIONS}

This paper reviews results from the literature on the effect of fiscal policy on income redistribution and provides a new decomposition of the redistributive effect of fiscal policy when individual units belong to identifiable groups. Sections 2 and 3 discussed the contributions by the literature on (i) the decomposition of the redistribution effect between a vertical effect and a reranking effect (an horizontal effect is absent in this paper because the data does not have ex ante equal individual units), (ii) the equivalence of the vertical effect and the Reynolds-Smolensky effect, (iii) the decomposition Reynolds-Smolensky coefficient of redistribution into size and progressive (Kakwani) effects, (iv) the decomposition of the Gini coefficient into within-group, between-group and transvariation effects, and (v) the decomposition of the reranking effect into within-group and across-group effects. This paper proposes a decomposition among within-group, between-group and transvariation effects in the presence of groups to the vertical / Reynolds-Smolensky effect and to the progressiveness effect of the Reynolds-Smolensky coefficient.

Sections 4 and 5 apply decompositions of Gini, RE and RS in the presence of groups for a selected case: Argentina in year 2010. We extend previous finding in the literature with the following results:

First, personal income inequality in year $2010\left(G_{X}=0.512\right)$ is distributed among within-group (50 percent), differences in groups' average income (26 percent) and income overlapping of units belonging to different groups (23 percent). Income redistribution of consolidated fiscal policy $(R E=0.098)$ represents 19 percent of ex ante inequality and is divided into a vertical effect $(V=0.102)$ and a compensating reranking effect $(R=0.004)$.

When provinces and income units are clustered in groups according to socioeconomic indicators (Núñez Miñana), both vertical and reranking effects distribute within- 
group and across-group evenly. The vertical / Reynolds-Smolensky effect is also decomposed in three parts: In the case of national-provincial analysis fiscal policy, provincial expenditure is found to be the most progressive tool, reducing inequality within groups (53 percent of the progressive effect of provincial expenditure), reducing disparities between groups (19 percent) and reducing overlapping of income units (28 percent). The progressive effect of national expenditure and the regressive effect of national taxes distribute evenly within and between groups. They do not contribute to increase or reduce overlapping of income units. The impact of provincial taxes is regressive, as the net result of within and overlapping effects, partially compensated by a progressive effect between groups.

In the case of cash-in kind analysis fiscal policy, both kinds of expenditures are progressive and include a 50-percent within-effect. Cash transfers have little transvariation effect (cash benefits do not change relative net-incomes to overlapping units from different groups). In general, taxes are regressive in all dimensions, except for a progressive transvariation effect for ex-ante taxes (which partially compensates a regressive effect caused by higher taxes paid, in average, by income units belonging to poorer groups).

Regional income inequality in year $2010\left(G_{X}=0.267\right)$ is distributed within-group (41 percent), differences in groups' average income (50 percent) and income overlapping of provinces belonging to different groups ( 9 percent). Income redistribution of consolidated fiscal policy $(R E=0.032)$ represents 12 percent of ex ante inequality. A vertical effect $(V=0.036)$ is partially compensated by reranking $(R=0.003)$.

Changes in average income between groups represent 72 percent of the across groups vertical effect. Reranking is mostly explained by narrowing of differences across groups. Within-group effects are small for both components of redistribution. Qualitative results from the decomposition of the Reynolds-Smolesnky effect are quite similar to those discussed for personal distribution of income. A first difference concerns the main factor of progressiveness of national and provincial expenditures: between-group effects are equal and within-group effects are weaker than those corresponding to personal income redistribution. A second difference is that taxes are regressive in all dimensions for both decompositions of fiscal policy (nationalprovincial and cash-in kind).

The results obtained for the transvariation effects are interesting because an important question in the theory of fiscal federalism is the relevant dimension of distribution: regional distribution, personal distribution or both?. As stated by Oates, “...The problem is that even relatively poor communities usually contain some wealthy persons, and, similarly, rich jurisdictions often have some poor residents..." (Oates, 1972, p.31). As a result, in some cases, fiscal policy will tend to move from lower-income units to relatively wealthy individuals. In the case of Argentina, the transvariation effects of national fiscal variables improve income distribution but provincial taxes go in the opposite direction (poor income units in high-income groups pay more provincial taxes than rich income units from low-income groups). 
The findings of this paper may also be useful for the design of fiscal policy in a federal country like Argentina where regional and personal distribution of income is one of many sources of conflicts in the public policy arena. They were put forward since the time of the national organization and the National Constitution of 1853 and the concern remains until now; for example, the Constitution of 1994 ordered the enacting of a new Revenue Sharing Law by the end of 1996. After more than 25 years, the law has not been passed yet. Fiscal policy issues include, among others, rebalancing expenditures among different kinds or levels of governments, as well as the re-designing the tax system and eliminating tradeoffs observed from the current context.

A final observation is in order. The methodology developed is useful to identify the effects within groups, between groups and among overlapping units, and whether there are tensions among them, but each classification may display different results. This may suggest a careful selection of groups, depending on the objective sought by the analyst or the policy maker. 


\section{APPENDIX A}

\section{A.1. Decomposition of Gini coefficients}

In this Appendix we describe the Gini and concentration indexes used throughout the paper. Let $X=\left\{x_{i}\right\}$ and $Y=\left\{y_{i}\right\}$ be two income distributions. The Gini coefficient for a distribution, say $X$, is presented in three different versions

$$
G_{X}=\left\{\begin{array}{c}
\frac{1}{2 \mu_{X}} \sum_{i=1}^{N} \sum_{j=1}^{N}\left|x_{i}-x_{j}\right| \cdot p_{i} \cdot p_{j} \\
\frac{1}{\mu_{X}} \sum_{i=1}^{N} \sum_{j=1}^{N} \max \left\{0 ; x_{i}-x_{j}\right\} \cdot p_{i} \cdot p_{j} \\
\frac{1}{2 \mu_{X}} \sum_{i=1}^{N} \sum_{j=1}^{N}\left(x_{i}-x_{j}\right) \cdot p_{i} \cdot p_{j} \cdot I\left\{r_{X}\left(x_{i}\right)-r_{X}\left(x_{j}\right)\right\}
\end{array}\right.
$$

where $p_{i}$ is the (population) weight of income unit $i$ and $\mu_{X}$ is the average income corresponding to distribution $X$. The indicator function $I\left\{r_{X}\left(x_{i}\right)-r_{X}\left(x_{j}\right)\right\}=I_{i-j}^{X}$ is such that

$$
I(h)=\left\{\begin{array}{c}
1 \text { if } h \geq 0 \\
-1 \text { if } h<0
\end{array}\right.
$$

These are three definitions among a long list of alternative definitions of the Gini coefficient of inequality.

Consider the case of a population partitioned in $S$ groups, ordered according to average income within groups ( $s>r$ iff $\mu_{X, s}>\mu_{X, r}$ ). The Gini coefficient for distribution $X$ can be decomposed into three effects:

$$
G_{X}=G_{X}^{W}+G_{X}^{A}=G_{X}^{W}+G_{X}^{T}+G_{X}^{B}
$$

where $G_{X}{ }^{W}$ is a within-group component, $G_{X}{ }^{T}$ stands for a transvariation / overlapping, $G_{X}{ }^{B}$ is a between-groups component, and $G_{X}{ }^{A}$ corresponds to an across-groups component (which is the sum of the between and overlapping effects).

There are several representations of the components. For convenience, we illustrate the decomposition followed by Dagum (1997) and Monti et al. (2012): 17

17 Alternative representations can be obtained from Bhattacharya-Mahalanobis (1967) and Pyatt (1976), also used by Dieguez and Petrecolla (1978) and Cont and Porto (1998). 


$$
\begin{gathered}
G_{X}^{W}=\frac{1}{2 \mu_{X}} \sum_{s=1}^{S}\left[\sum_{l=1}^{N_{s}} \sum_{m=1}^{N_{s}}\left(x_{l, s}-x_{m, s}\right) \cdot p_{l, s} \cdot p_{m, s} \cdot I_{l, s-m, s}^{X}\right] \\
G_{X}^{T}=\frac{1}{\mu_{X}} \sum_{s=2}^{S} \sum_{r=1}^{s-1}\left[2 \sum_{l=1}^{N_{s}} \sum_{\substack{m=1 \\
\left\{x_{l, s}<x_{m, r}\right\}}}^{N_{r}}\left(x_{m, r}-x_{l, s}\right) \cdot p_{l, s} \cdot p_{m, r}\right]
\end{gathered}
$$

The $G_{X}{ }^{T}$ component is calculated after sorting groups $s$ in increasing order of average income $\left(\mu_{X, S}\right)$, so that it adds all income differentials such that $\mu_{X, s}>\mu_{X, r}$ and $x_{m, r}>x_{l, s}$ (see that first sum goes from $s=2$ to $S$, and the second sum goes from $r=1$ to $s$ - 1 ). As with the Pyatt decomposition, $G_{X}^{T}=0$ if $\min \left\{x_{l, s}\right\}>\max \left\{x_{m, r}\right\}$ for all pairs of groups.

Finally,

$$
G_{X}^{B}=\frac{1}{\mu_{X}} \sum_{s=2}^{S} \sum_{r=1}^{s-1}\left(\mu_{X, s}-\mu_{X, r}\right) \cdot p_{s} \cdot p_{r}=\frac{1}{\mu_{X}} \sum_{s=2}^{S} \sum_{r=1}^{s-1}\left[\sum_{l=1}^{N_{s}} \sum_{m=1}^{N_{r}}\left(x_{m, r}-x_{l, s}\right) \cdot p_{l, s} \cdot p_{m, r}\right]
$$

and hence

$$
G_{X}^{A}=\frac{1}{2 \mu_{X}} \sum_{s=1}^{S} \sum_{r \neq s}\left[\sum_{l=1}^{N_{s}} \sum_{m=1}^{N_{r}}\left(x_{l, s}-x_{m, r}\right) \cdot p_{l, s} \cdot p_{m, r} \cdot I_{l, s-m, s}^{X}\right]
$$

The same definitions apply to the Gini coefficient corresponding to the $Y$ distribution.

\section{A.2. Decomposition of concentration coefficients}

Monti et al. (2012) also show that the concentration coefficient of $Y$ distribution, while preserving the ordering from the $X$ distribution, is:

$$
C_{Y \mid X}=\frac{1}{2 \mu_{Y}} \sum_{i=1}^{N} \sum_{j=1}^{N}\left(y_{i}-y_{j}\right) p_{i} p_{j} . I_{i-j}^{Y \mid X}
$$

where the indicator function $I(h)$ previously defined applies to the ordering $Y \mid X$ (i.e., the values $y_{i}$ are ordered according to increasing values of $x_{i}$, and the indicator $I_{i-j}^{Y \mid X}$ takes value of 1 if $x_{i} \geq x_{j}$ ). The difference between $G_{Y}$ and $C_{Y \mid X}$ arises when $x_{i}>x_{j}$ and $y_{i}<y_{j}$ (or vice-versa). The authors show that $C_{Y \mid X}$ can be decomposed in withinand across- effects: 


$$
C_{Y \mid X}=C_{Y \mid X}^{W}+C_{Y \mid X}^{A}
$$

where

$$
\begin{gathered}
C_{Y \mid X}^{W}=\frac{1}{2 \mu_{Y}} \sum_{s=1}^{S}\left[\sum_{l=1}^{N_{s}} \sum_{m=1}^{N_{s}}\left(y_{l, s}-y_{m, s}\right) \cdot p_{l, s} \cdot p_{m, s} \cdot I_{l, s-m, s}^{Y \mid X}\right] \\
C_{Y \mid X}^{A}=\frac{1}{2 \mu_{Y}} \sum_{s=1}^{S} \sum_{r \neq s}\left[\sum_{l=1}^{N_{s}} \sum_{m=1}^{N_{r}}\left(y_{l, s}-y_{m, r}\right) \cdot p_{l, s} \cdot p_{m, r} \cdot I_{l, s-m, r}^{Y \mid X}\right]
\end{gathered}
$$

This way, reranking $\left(R=G_{Y}-C_{Y \mid X}\right)$ can be decomposed into $R^{W}=G_{Y}^{W}-C_{Y \mid X}^{W}$ and $R^{A}=G_{Y}^{A}-C_{Y \mid X}^{A}$. Even though $C_{Y \mid X}^{A}$ can be decomposed into $C_{Y \mid X}^{B}$ and $C_{Y \mid X}^{T}$, Monti et al. (2012) show that $R^{T}=G_{Y}^{T}-C_{Y \mid X}^{T}$ and $R^{B}=G_{Y}^{B}-C_{Y \mid X}^{B}$ are not proper measures of reranking.

\section{A.3. Proof of Proposition 1}

In Section A.2 of this Appendix we stated that Monti et al. (2012) showed that $C_{Y \mid X}=C_{Y \mid X}^{W}+C_{Y \mid X}^{T}+C_{Y \mid X}^{B}$. Now take another distribution, say $Z$, such that groups are ordered according to a non-decreasing order of the mean $\mu_{X, s}$, and values $z_{i}$ are lined up in non-decreasing ordering of $x_{i}$ within each group $s$. The concentration coefficient $C_{Z \mid X}$ of $Z$ distribution, while preserving the ordering from the $X$ distribution, is:

$$
C_{Z \mid X}=\frac{1}{2 \mu_{Z}} \sum_{i=1}^{N} \sum_{j=1}^{N}\left(z_{i}-z_{j}\right) p_{i} p_{j} \cdot I_{i-j}^{Z \mid X}
$$

where $\mu_{Z}$ is the average of variable $z_{\mathrm{i}}$ and

$$
I_{i-j}^{Z \mid X}=I\left\{r_{Z}\left(z_{i}\right)-r_{Z}\left(z_{j}\right)\right\}, \text { where } I(h)=\left\{\begin{array}{c}
1 \text { if } h \geq 0 \\
-1 \text { if } h<0
\end{array}\right.
$$

It is straightforward to extend the decomposition of $C_{Z \mid X}$ as:

$$
C_{Z \mid X}=C_{Z \mid X}^{W}+C_{Z \mid X}^{A}=C_{Z \mid X}^{W}+C_{Z \mid X}^{B}+C_{Z \mid X}^{T}
$$


where

$$
\begin{gathered}
C_{Z \mid X}^{W}=\frac{1}{2 \mu_{Z}} \sum_{s=1}^{S}\left[\sum_{l=1}^{N_{s}} \sum_{m=1}^{N_{s}}\left(z_{l, s}-z_{m, s}\right) \cdot p_{l, s} \cdot p_{m, s} \cdot I_{l, s-m, s}^{Z \mid X}\right] \\
C_{Z \mid X}^{A}=\frac{1}{2 \mu_{Z}} \sum_{s=1}^{S} \sum_{r \neq=s}\left[\sum_{l=1}^{N_{s}} \sum_{m=1}^{N_{r}}\left(z_{l, s}-z_{m, r}\right) \cdot p_{l, s} \cdot p_{m, r} \cdot I_{l, s-m, r}^{Z \mid X}\right] \\
G_{Z \mid X}^{B}=\frac{1}{\mu_{Z}} \sum_{s=2}^{S} \sum_{r=1}^{s-1}\left(\mu_{Z, s}-\mu_{Z, r}\right) \cdot p_{s} \cdot p_{r} \\
C_{Z \mid X}^{T}=\frac{1}{\mu_{Z}} \sum_{s=2}^{S} \sum_{r=1}^{s-1}\left[\sum_{l=1}^{\left.\sum_{s=1}^{N_{s}} \sum_{m=1}^{N_{r}}\left(z_{m, r}-z_{l, s}\right) \cdot p_{l, s} \cdot p_{m, r}\right\}}\right.
\end{gathered}
$$




\section{APPENDIX B}

\section{TABLE B1}

REGIONAL INDICATORS, 2010

\begin{tabular}{|c|c|c|c|c|c|c|c|c|c|}
\hline Jurisdiction & Group & $\begin{array}{l}\text { Surface } \\
(\mathrm{sq} \mathrm{km})\end{array}$ & $\begin{array}{c}\text { Population } \\
\text { ('000) }\end{array}$ & $\begin{array}{c}\text { Population } \\
\text { density }\end{array}$ & $\begin{array}{c}\text { GGP } \\
\text { (million } \\
\text { dollars) }\end{array}$ & $\begin{array}{c}\text { Per capita } \\
\text { GGP ('000 } \\
\text { dollars) }\end{array}$ & $\begin{array}{c}\text { Extended } \\
\text { per capita } \\
\text { GGP ('000 } \\
\text { dollars) }\end{array}$ & $\begin{array}{l}\text { HDI } \\
(2011)\end{array}$ & UBN \\
\hline Buenos Aires & A & 307,571 & 15,316 & 49.8 & 130,332 & 8,510 & 8,116 & 0.84 & $8 \%$ \\
\hline City Bs As & A & 200 & 3,058 & 15291.5 & 84,128 & 27,508 & 26,953 & 0.89 & $6 \%$ \\
\hline Catamarca & $\mathrm{L}$ & 102,602 & 404 & 3.9 & 3,253 & 8,047 & 9,075 & 0.84 & $11 \%$ \\
\hline Chaco & $\mathrm{L}$ & 99,633 & 1,071 & 10.8 & 4,117 & 3,844 & 5,135 & 0.81 & $18 \%$ \\
\hline Chubut & LD & 224,686 & 471 & 2.1 & 5,854 & 12,436 & 11,292 & 0.85 & $8 \%$ \\
\hline Córdoba & A & 165,321 & 3,397 & 20.5 & 26,671 & 7,852 & 7,567 & 0.86 & $6 \%$ \\
\hline Corrientes & $\mathrm{L}$ & 88,199 & 1,036 & 11.7 & 4,259 & 4,112 & 4,721 & 0.83 & $15 \%$ \\
\hline Entre Ríos & I & 78,781 & 1,282 & 16.3 & 7,861 & 6,132 & 6,671 & 0.84 & $8 \%$ \\
\hline Formosa & $\mathrm{L}$ & 72,066 & 556 & 7.7 & 1,919 & 3,453 & 5,522 & 0.81 & $20 \%$ \\
\hline Jujuy & $\mathrm{L}$ & 53,219 & 698 & 13.1 & 3,089 & 4,422 & 5,609 & 0.83 & $15 \%$ \\
\hline La Pampa & LD & 143,440 & 341 & 2.4 & 1,823 & 5,338 & 6,704 & 0.86 & $4 \%$ \\
\hline La Rioja & $\mathrm{L}$ & 89,680 & 355 & 4.0 & 1,526 & 4,294 & 6,783 & 0.83 & $12 \%$ \\
\hline Mendoza & A & 148,827 & 1,766 & 11.9 & 12,282 & 6,956 & 7,181 & 0.85 & $8 \%$ \\
\hline Misiones & $\mathrm{L}$ & 29,801 & 1,111 & 37.3 & 7,402 & 6,660 & 7,199 & 0.82 & $16 \%$ \\
\hline Neuquén & LD & 94,078 & 565 & 6.0 & 7,780 & 13,764 & 14,249 & 0.86 & $10 \%$ \\
\hline Río Negro & LD & 203,013 & 604 & 3.0 & 4,790 & 7,933 & 9,066 & 0.85 & $9 \%$ \\
\hline Salta & I & 155,488 & 1,267 & 8.2 & 5,006 & 3,950 & 4,255 & 0.83 & $19 \%$ \\
\hline San Juan & I & 89,651 & 715 & 8.0 & 3,293 & 4,605 & 5,102 & 0.83 & $10 \%$ \\
\hline San Luis & I & 76,748 & 457 & 6.0 & 3,020 & 6,611 & 8,010 & 0.83 & $8 \%$ \\
\hline Santa Cruz & LD & 243,943 & 234 & 1.0 & 3,767 & 16,092 & 16,444 & 0.87 & $8 \%$ \\
\hline Santa Fe & A & 133,007 & 3,285 & 24.7 & 32,966 & 10,035 & 9,204 & 0.85 & $6 \%$ \\
\hline S. del Estero & $\mathrm{L}$ & 136,351 & 884 & 6.5 & 3,340 & 3,781 & 5,226 & 0.81 & $18 \%$ \\
\hline $\begin{array}{l}\text { Tierra del } \\
\text { Fuego }\end{array}$ & LD & 21,571 & 134 & 6.2 & 2,551 & 19,081 & 19,381 & 0.88 & $14 \%$ \\
\hline Tucumán & I & 22,524 & 1,512 & 67.1 & 6,615 & 4,377 & 5,109 & 0.84 & $13 \%$ \\
\hline Argentina & & $2,780,400$ & 40,519 & 14.6 & 367,643 & 9,073 & 9,082 & 0.85 & $9 \%$ \\
\hline (std. deviation) & & & & & & 0.64 & 0.59 & 0.03 & 0.51 \\
\hline Advanced & & 754,926 & 26,822 & 35.5 & 286,379 & 10,677 & 10,266 & 0.85 & $7 \%$ \\
\hline Group & & & & & & & & & \\
\hline Low Density & & 930,731 & 2,349 & 2.5 & 26,565 & 11,309 & 11,740 & 0.86 & $8 \%$ \\
\hline Intermediate & & 423,192 & 5,233 & 12.4 & 25,795 & 4,929 & 5,537 & 0.84 & $12 \%$ \\
\hline Lagged & & 671,551 & 6,115 & 9.1 & 28,905 & 4,727 & 5,898 & 0.82 & $16 \%$ \\
\hline
\end{tabular}

Source: Own elaboration based on INDEC Argentina (surface, population, and UBN - Unsatisfied Basic Needs), and United Nations (HDI - Human Development Index). GGP published by Council of Federal Investment (CFI) until 2006 and then updated by regional drivers, and expanded to the GDP using national accounts, with base 1993 (the government updated statistics in 2014, from base 1993 to base 2004; we maintain the base-1993 statistics because they are consistent with the data base of companion papers). Note: A: Advanced; I: Intermediate; LD: Low Density; L: Lagged. The classification is based on population, population dispersion and development gap measured with quality of human resources, quality of housing and automobiles per inhabitant. The exchange rate was 3.93 Argentine pesos per dollar in year 2010. 


\section{REFERENCES}

AHUMADA, H., A. CANAVESE, L. GASPARINI, A. PORTO and P. SANGUINETTI (1996). "Impacto distributivo del presupuesto público. Aspectos Metodológicos", Serie Política Fiscal 77, CEPAL.

ATKINSON, A. (1980). "Horizontal equity and the distribution of the tax burden", in H. Aaron and M. Boskins, The Economics of Taxation, Washington D.C.: Brookings.

ARONSON, J., P. JOHNSON and P. LAMBERT (1994). "Redistributive effect and unequal income tax treatment", Economic Journal, 104(423), pp. 262-270.

ARONSON, J. P. LAMBERT (1994). "Decomposing the Gini coefficient to reveal vertical, horizontal and reranking effects of income taxation", National Tax Journal, 47(2), pp. 273-294.

BHATTACHARYA, N. B. MAHALANOBIS (1967). "Regional disparities in household consumption in India", Journal of the American Statistical Association, 62(317), pp. 143-161.

CALVO, E. and V. MURILLO (2004). "Who Delivers? Partisan Clients in the Argentine Electoral Market", American Journal of Political Science, 48(4), pp. 742-757.

CONT, W. and A. PORTO (2014). "Personal and regional redistribution through public finance in a federal setting”, The Quarterly Review of Economics and Finance, 54, pp. 563-578.

CONT, W. and A. PORTO (2016a). "Fiscal policy and income distribution. Argentina 1995 - 2010", Review of Economics \& Finance, 6(2), pp. 75-92.

CONT, W. and A. PORTO (2016b). "Geografía de la desigualdad en la distribución personal del ingreso y en el impacto distributivo de la política fiscal. Argentina 1995-2010”, LI Reunión Anual de la Asociación Argentina de Economía Política, Tucumán.

CONT, W. and A. PORTO (2017), "Geografía de la distribución del ingreso y del impacto distributivo de la política fiscal. Argentina 1995-2010. Cuantificación de variables por jurisdicciones. Datos y metodología". Document in Spanish, available here.

CONT, W., A. PORTO and P. JUARROS (2017). "Regional income redistribution and risk-sharing: Lessons from Argentina", Journal of Applied Economics, 20(2), pp. 241-269.

DAGUM, C. (1997). "A new decomposition of the Gini Income Inequality Ratio", Empirical Economics, 22, pp. 515-531.

DEATON, A. (1996). The analysis of household surveys: A microeconometric approach to development policy, Johns Hopkins University Press, Baltimore MD.

DIEGUEZ, H. and A. PETRECOLLA (1979). "Distribución del ingreso en el Gran Buenos Aires", Serie Economía, Instituto Torcuato Di Tella, Buenos Aires.

DUCLOS, J. (1993). "Progressivity, redistribution and equity, with application to the British Tax and Benefit system", Public Finance, 48(3), pp. 350-365.

DUCLOS J., V. JALBERT and A. ARAAR (2003). "Classical horizontal inequality and reranking: an integrating approach", in Amiel, Y. and J. Bishop, Fiscal Policy, Inequality and Welfare (Research on Economic Inequality, Volume 10), Emerald Group Publishing Limited, pp. 65-100.

FELDSTEIN, M. (1976). "On the theory of tax reform", Journal of Public Economics, 6(1-2), pp. 77-104.

GIMPELSON, V. and D. TREISMAN (2002). "Fiscal games and public employment", World Politics, 54(2), pp. 145-183.

GRIFFITHS, W. (2008). "On Dagum's Decomposition of the Gini Coefficient”, The University of Melbourne Department of Economics, Research Paper Number 1054.

JENKINS, S. (1988). "Reranking and the analysis of income redistribution", Scottish Journal of Political Economy, 35(1), pp. 65-76.

KAKWANI, N. (1977). "Measurement of tax progressivity: an international comparison", Economic Journal, vol. 87, pp. 71-80.

KAKWANI, N. (1984). "On the measurement of tax progressivity and redistributive effect of taxes with applications to horizontal and vertical equity". Advances in Econometrics, vol. 3, pp. 149-168.

KAKWANI, N. (1986). Analyzing Redistribution Policies. Cambridge: University Press.

KIM, K. and P. LAMBERT (2009). "Redistributive effect of U.S. taxes and public transfers, 1994-2004", Public Finance Review, pp. 37(1), pp. 3-26.

KING, M. (1983). "An index of inequality: With implications to horizontal equity and social Mobility", Econometrica, 51(1), pp. 99-115. 
LAMBERT, P. (1985). "On the redistributive effect of taxes and benefits", Scottish Journal of Political Economy, 32(1), pp. 39-54.

LAMBERT, P. (1988). "Net fiscal incidence progressivity: some approaches to measurement" in Eichhorn, W., Measurement in Economics: Theory and Applications of Economic Indices, Heidelberg: PhysicaVerlag, pp. 519-532.

LAMBERT, P. and R. ARONSON (1993). "Inequality Decomposition Analysis and the Gini Coefficient Revisited", The Economic Journal, 103(420), pp. 1221-1227.

LERMAN, R. and S. YITZHAKI (1995). "Changing ranks and the inequality impacts of taxes and transfers", National Tax Journal, 48(1), pp. 45-59.

MONTI, M., M. MUSSINI and A. VERNIZZI (2012). "The Decomposition of the Atkinson-Plotnick-Kakwani Re-Ranking Measure", Statistica applicata - Italian Journal of Applied Statistics, 22(2), pp. 177-198.

MOOKHERJEE, D. and A. SHORROCKS (1982). "A decomposition analysis of the trend in U.K. income inequality", Economic Journal, 92(368), pp. 886-902.

MONTI, M. (2007). "A note on the Dagum decomposition of the Gini inequality index", DEAS Università degli studi di Milano, WP 2007-16.

MUSGRAVE, R. (1964). "Estimating the distribution of the tax burden", in Clark, C. and G. Stuvel, Income redistribution and the statistical foundations of economic policy, income and wealth, Bowes and Bowes, Cambridge.

MUSGRAVE, R. (1996). "The role of the state in fiscal theory", International Tax and Public Finance, 3, pp. 247-258.

MUSGRAVE, R. and T. THIN (1948). “Income tax progression, 1929-48”, Journal of Political Economy, 56(6), pp. 498-514.

NUÑEZ MIÑANA, H. (1972). "Indicadores de Desarrollo Regional en la República Argentina: Resultados Preliminares", Documento Interno $\mathrm{N}^{\circ} 10$ del Instituto de Investigaciones Económicas, Universidad Nacional de La Plata. Republished in: Porto, A., Finanzas Públicas y Economía Espacial. Universidad Nacional de La Plata (1995), pp. 11-24.

OATES, W. (1972). Fiscal Federalism, Harcourt Brace Jovanovich, Inc., USA.

PFÄHLER, W. (1987). "Redistributive Effects of Tax Progressivity: Evaluating a General Class of Aggregate Measures", Public Finance/ Finances Publiques, 42(1), pp. 1-31.

PLOTNICK, R. (1981). "A measure of horizontal inequity”, Review of Economics and Statistics, 63(2), pp. 283-288.

PORTO, A. and W. CONT (1998). "Presupuestos provinciales, transferencias intergubernamentales y equidad”, Desarrollo Económico, 38, Special Issue, pp. 267-291.

PORTO, A. (2017). "Transferencias intergubernamentales, igualación fiscal y reordenamiento de las provincias", LII Annual Meeting of Asociación Argentina de Economía Política.

PYATT, G. (1976). "The interpretation and disaggregation of Gini coefficients", The Economic Journal, 86(342), pp. 243-255.

REYNOLDS, M. and E. SMOLENSKY (1977). Public Expenditures, Taxes and the Distribution of Income, American Press, New York.

SCHILLER, B. (1977). "Relative Earnings Mobility in the United States", American Economic Review, 67(5), pp. 926-941.

SILBER, J. (1989). "Factor components, population subgroups and the computation of the Gini index of inequality", Review of Economics and Statistics, 71(1), pp. 107-15.

URBAN, I. (2009a). "Indices of redistributive effect and reranking: Reinterpretation", ECINEQ WP $2009-147$.

URBAN, I. (2009b). "Kakwani decomposition of redistributive effect: Origins, critics and upgrades", ECINEQ WP $2009-148$.

URBAN, I. and P. LAMBERT (2008). "Redistribution, horizontal inequity and reranking: how to measure them properly", Public Finance Review, 36(5), pp. 563-587.

van de VEN, J., J. CREEDY and P. LAMBERT (2001). "Close equals and calculation of the vertical, horizontal and reranking effects of taxation", Oxford Bulletin of Economics and Statistics, 63(3), pp. 381-394.

WAGSTAFF, A. (2009). "Re-ranking and pro-poor growth: decompositions for China and Vietnam", Journal of Development Studies, 45(9), pp. 1403-1425. 